\title{
Continuous monitoring of turbidity and conductivity: a reliable, easy and economic tool for sanitation management
}

\author{
T. Bersinger ${ }^{1,2}$, T. Pigot ${ }^{2}$, G. Bareille ${ }^{1}$ \& I. Le Hecho ${ }^{1}$ \\ ${ }^{1}$ Laboratoire de Chimie Analytique Bio-Inorganique et Environnement, \\ UMR 5254 CNRS/UPPA, IPREM Pau, France \\ ${ }^{2}$ Equipe de Chimie Physique, UMR 5254 CNRS/UPPA, IPREM Pau, \\ France
}

\begin{abstract}
To monitor sanitation, the urban catchment of Pau urban area (south west France), which is about $50 \mathrm{~km}^{2}$ with about 150000 inhabitants was equipped with four rain gauges, thirty four flowmeters, two turbidimeters and one conductimeter. Good correlations were obtained between turbidity, Total Suspended Solids (TSS) and Chemical Oxygen Demand (COD) on the one hand and conductivity and total nitrogen on the other. These probes were installed in March 2012 and allowed an instantaneous and continuous estimation of pollutants concentrations from this date. In this paper results from November 2012 are presented. Firstly turbidity and conductivity raw data show different trends during the study period depending on rain events. Mass/volume curves have been established and used to compare the behaviour of the network during different rain events. Very different curves are obtained between TSS and total nitrogen. Finally, pollutant fluxes are calculated daily during the month of November. This presentation allows the synthesis of the data and a global comprehension and monitoring of the sewer system. These results highlight the potential of online monitoring to better understand the behaviour of the sewer network on long or short term scales. This could be a useful tool to manage wastewater treatment.

Keywords: continuous monitoring, turbidity, conductivity, total suspended solid, chemical oxygen demand, total nitrogen, pollutant fluxes.
\end{abstract}




\section{Introduction}

The European Water Frame-work Directive has targeted the aim of reaching "the good ecological and chemical status” for all of Europe's aquatic environments by 2015 WFD [1]. The impact of combined sewer overflows (CSO) on the quality of receiving environment has been widely demonstrated. CSOs collect both wastewaters and rainfall waters that may have high loads of anthropogenic pollutants (Gromaire et al. [2], Chebbo and Gromaire [3], Gasperi et al. [4]). In such a context, the reduction of the impact of wastewater effluents from CSO has become an important priority and urban administrations have to take some measures to decrease the pollutant transfer towards the receiving environments. This challenge requires a perfect knowledge of the dynamics of the wastewater sewer system. Thus, determination of pollutant fluxes and loads is compulsory. For accurate establishment of the sewer system fingerprint, online monitoring could be required. As a result, continuous monitoring of untreated wastewaters via CSO becomes a key issue for wastewater treatment management and protection of receiving environment. Monitoring based only on sample analyses being technically and economically unrealistic it is necessary to turn to an indirect online determination of pollutant parameters. This can be done via the measurement of physical parameters such as turbidity as was recently demonstrated (Lacour et al. [5], Joannis et al. [6], Métadier and BertrandKrajewski [7]). Turbidity online measurements allow the monitoring of global pollutant loads such as Total Suspended Solids (TSS) and Chemical Oxygen Demands (COD) (Lawler et al. [8], Aumond and Joannis [9]). This further provides the dynamic of the studied systems with a higher resolution than analyses at laboratory scale. This could lead to a better management of CSO and wastewater treatment plant (WWTP) (Boutayacht et al. [10], Rosier et al. [11]). Nevertheless, the use of online turbidity measurements to assess pollutant loads requires calibration, statistical work with continuous time series data to establish turbidity/TSS and turbidity/COD reliable relationships that must be established for each studied site.

In this study, we present the main results obtained for Pau urban sewer system monitoring (south-west France). Firstly, relationships between turbidity/TSS, turbidity/COD and for the first time conductivity/Total nitrogen as a function of different and representative rainfall events are demonstrated. The established correlations are thus used to assess continuous COD, TSS and total nitrogen load for 15 days in November 2012.

\section{Materials and method}

\subsection{Study site}

The combined sewer system of the urban area of the city of Pau (south-west France) drains about $50 \mathrm{~km}^{2}$ with 150000 inhabitants (Figure 1). The majority of the surface is composed of residential neighborhoods; several areas of commercial and industrial activities are also present. The ground impervious 
ratio is about $80 \%$. The sewer network is $800 \mathrm{~km}$ long and more than $75 \%$ of the population is connected to a combined sewer. Average slope of this sewer network is about $1 \%$. Each day, about $50000 \mathrm{~m}^{3}$ are treated to the wastewater treatment plant (WWTP). This study area covers the entirety of the catchment system as well as the sewer network, the CSO, the wastewater treatment plant and the receiving water (river "Gave de Pau"). That makes it possible to have a global comprehensive view of wastewater management from the sources until the discharge in the receiving environment.

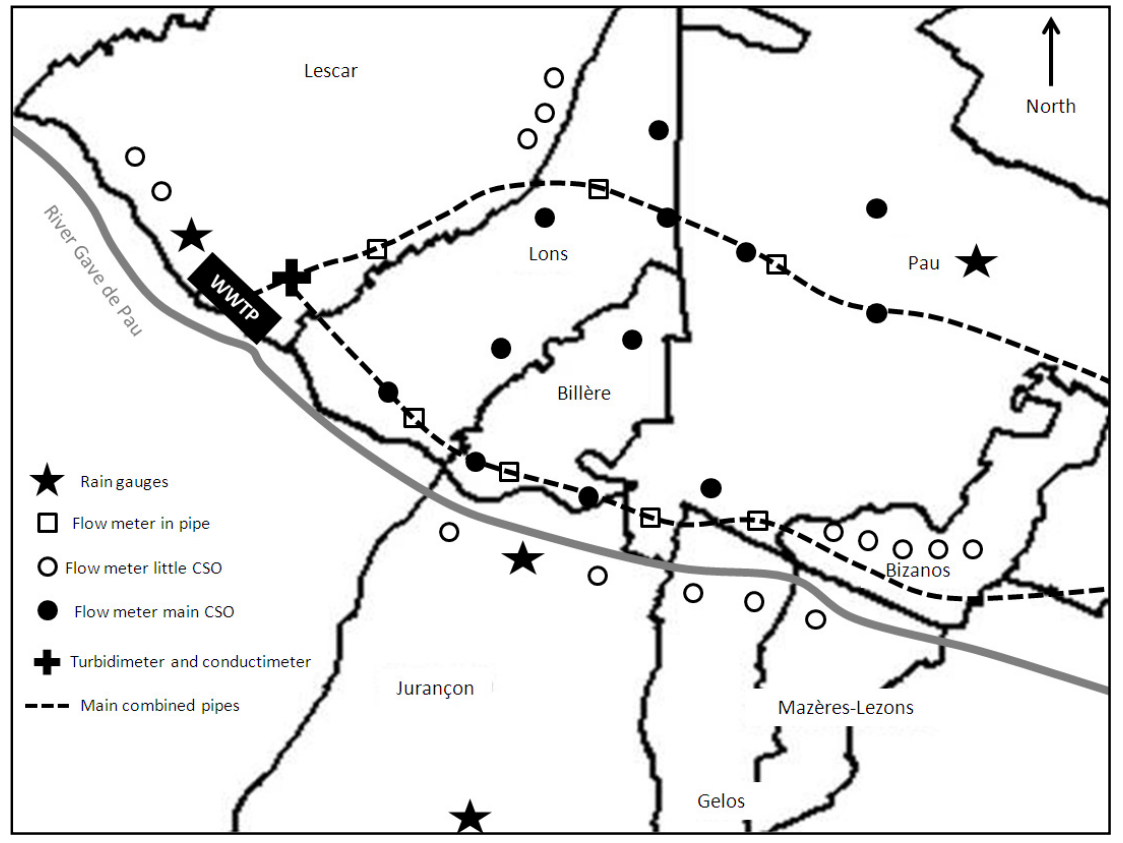

Figure 1: $\quad$ Study area and major equipment.

\subsection{Sensors and on line equipment}

The study area is equipped with 4 tipping-bucket rain gauges PULSONIC installed in 2009. Measurements range between 0 and $450 \mathrm{~mm} / \mathrm{h}$ with $0.2 \mathrm{~mm}$ accuracy. Data are sent daily on a computer and exploited using PULSOWIN software.

The entire network is equipped with seven flow meters based on acoustic Doppler principles (Mainstream, Hydreka). The data are measured each 5 minutes since 2009 and are transmitted automatically towards an acquisition station on which the data are analyzed with WINFLUID software.

Moreover, 27 CSOs have been also equipped with flow meters since 2009.

For the monitoring of pollutant concentrations, 2 turbimeters and 1 conductimeter were installed in March 2012 downstream from the junction of the 
two main pipes just before the WWTP. This site was chosen because it allows the monitoring, in the same time, of wastewater discharged at the main CSO of the study area and wastewater directed towards the WWTP (Figure 1). These probes are two nephelometrics turbidimeters: the first one is a TS 1000 Hydreka turbidimeter with a 0 to 1000 NTU range, measurements are stored in an Octopus recorder and data are downloaded each week on a laptop computer using WINFLUID software. The second one is a Hach Lange Solitax sc turbidimeter with a 0 to 4000 NTU range, measurements are stored in a Hach Lange SC200 recorder. Data are downloaded each week on a laptop computer using SD card. For these two probes, the mean turbidity is estimated every $5 \mathrm{~min}$ on the basis of $15 \mathrm{~s}$ data integrations. Turbidimeters are calibrated with formazine solution. The turbidity measurements can be disturbed by a waste in front of the probe. A technique for the removal of these outliers has been implemented.

The conductivity probe is an inductive condictimeter 3700 sc Hach Lange with 0 to $10000 \mu \mathrm{S} / \mathrm{cm}$ range. Measurements are stored in a Hach Lange SC200 recorder. Data are downloaded each week on a laptop computer using SD card. Conductimeter is calibrated with $\mathrm{NaCl}$ solution.

\subsection{Sampling and analyzes}

For all samples, automatic samplers ISCO 3700 Neotek are used. The samples are systematically kept cold $\left(4^{\circ} \mathrm{C}\right)$ and analyzed in the laboratory within 24 hours following the protocols described below. All analyzes are performed on the raw sample using the following methods. The measurement of turbidity and conductivity is made with the probes described above. Total Suspended Solids (TSS) are analyzed according to the NF T 90-105 standard. Chemical Oxygen Demand (COD) is determined with Aqualytic colorimetric kits after validation according to the normalized standard NF $\mathrm{T}$ 90-101. For total nitrogen measurements, a Simadzu TOC - V CSN is used. For all these analyses, triplicates, standards and blanks are done.

\subsection{Correlation functions}

108 samples of wastewater were analyzed to establish the correlation between turbidity/TSS and COD. 70 samples were used for the correlation between total nitrogen and conductivity. The samples were taken from the entire network during dry and wet weather. Positive correlations between TSS/turbidity, COD/turbidity and total nitrogen/conductivity were found to be consistent (Figure 2). The corresponding correlation functions were established:

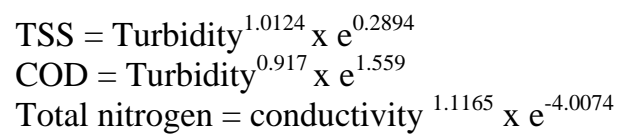



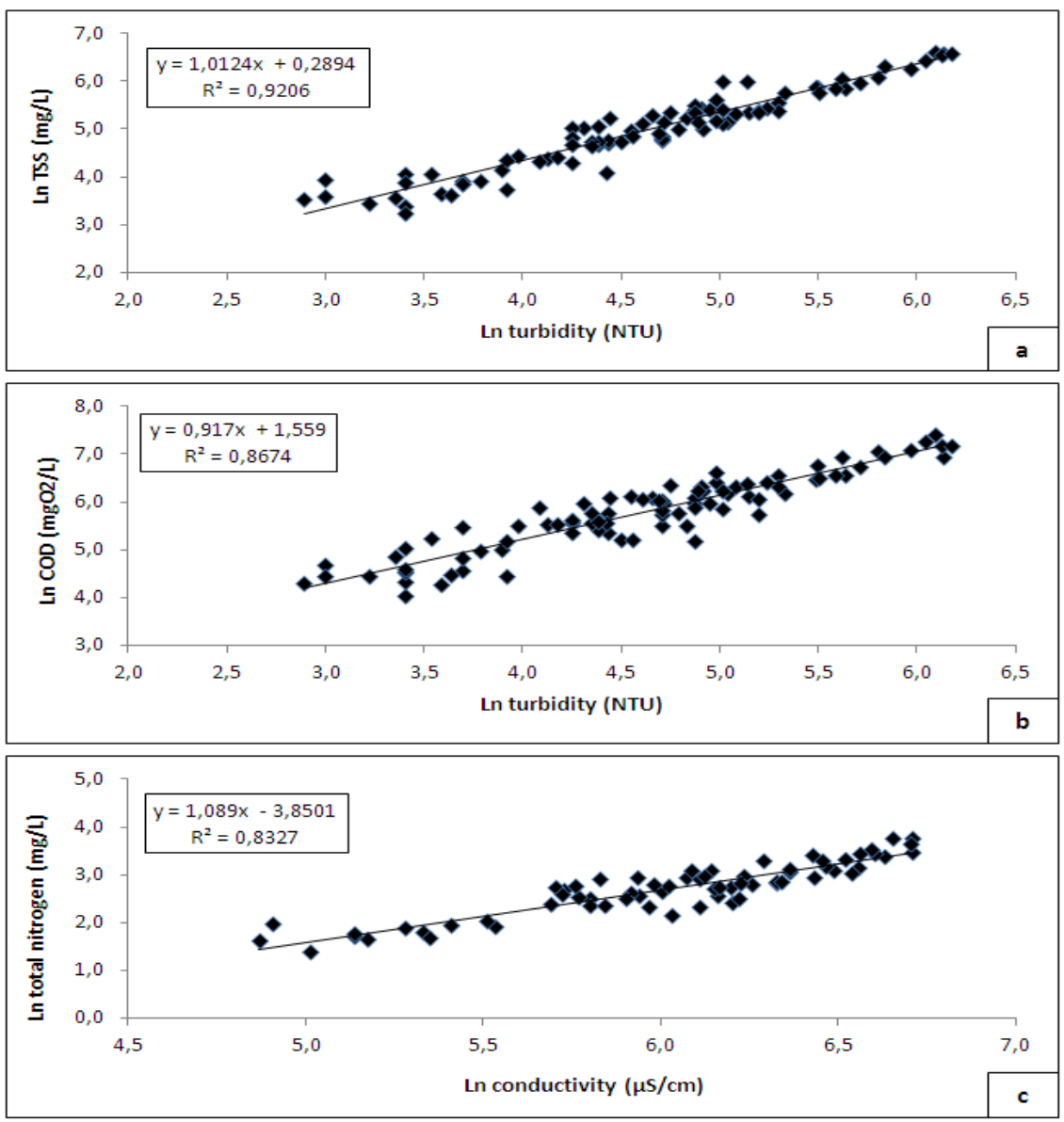

Figure 2: $\quad$ Relationships between (a) ln TSS / ln turbidity, (b) $\ln$ COD / ln turbidity and (c) ln total nitrogen / ln conductivity.

Correlation coefficients are between 0.83 and 0.92 and allow a good estimation of concentrations of pollutants.

\section{Results and discussion}

Monitoring has been conducted since March 2012, it still goes on today. This section is devoted to the use of data recorded by all sensors from $15^{\text {th }}$ to $30^{\text {th }}$ November 2012. This month was chosen because it is representative of the different weather situations that may be encountered in the study area with alternating periods of dry and wet weather and rainfall more or less intense.

Firstly, the raw signal recordings of the sensors are presented; then mass/volume curves for each rain main event are established. Finally, the fluxes of pollutants are calculated daily and are presented and interpreted last. 
Before the use of data, the validity of linear correlation and validity of probes has been checked during all the duration of the study.

\subsection{Temporal variability of the raw signal}

Figure 3 gathers all the data recorded during the second half of November. From the top to the lower part of the figure, rainfalls, treated flow at the WWTP, wastewater discharged at the CSO, conductivity and turbidity are showed.

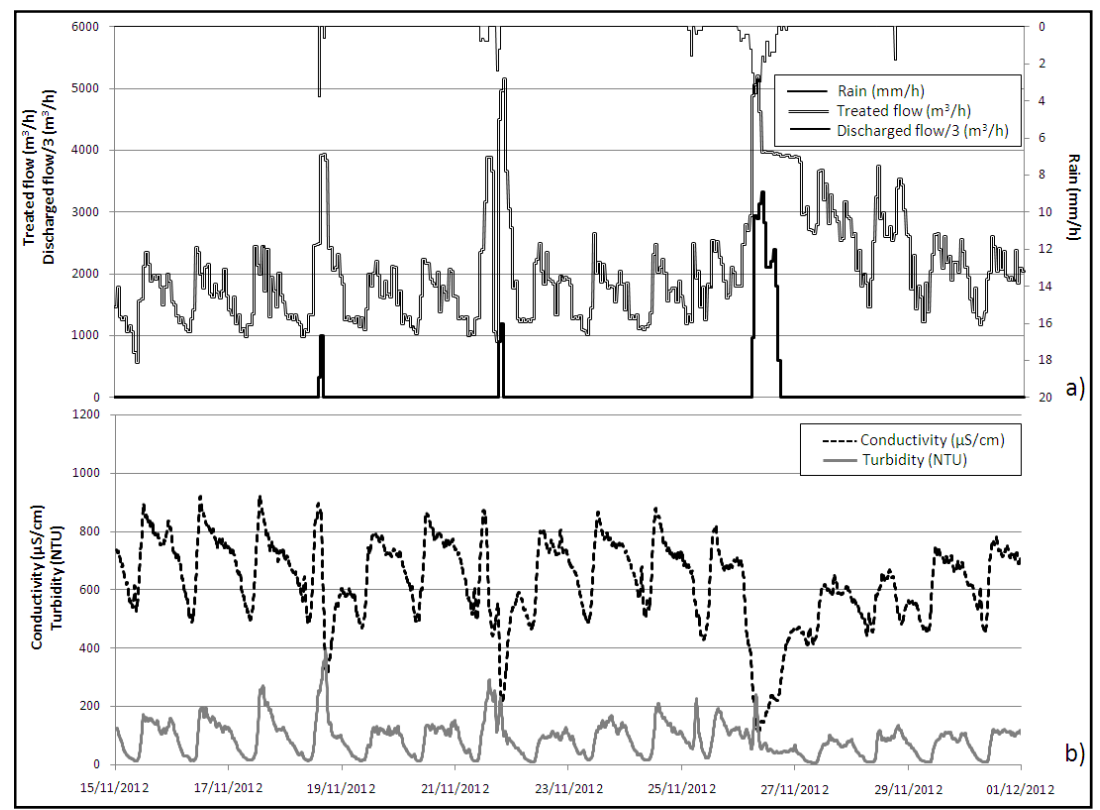

Figure 3: Overall presentation of continuous monitoring during the month of November 2012 a) rain, treated and discharged flows b) conductivity and turbidity.

Rainfall events recorded during November and their characteristics are listed in Table 1 for an easier discussion.

Table 1: $\quad$ Characteristics of rain events during November.

\begin{tabular}{|c|c|c|c|c|c|}
\hline $\begin{array}{c}\text { Date of } \\
\text { rain } \\
\text { event }\end{array}$ & $\begin{array}{c}\text { Rainfall } \\
(\mathrm{mm})\end{array}$ & $\begin{array}{c}\text { Duration } \\
(\mathrm{h})\end{array}$ & $\begin{array}{c}\text { Average } \\
\text { intensity } \\
(\mathrm{mm} / \mathrm{h})\end{array}$ & $\begin{array}{c}\text { Maximum } \\
\text { intensity } \\
(\mathrm{mm} / \mathrm{h})\end{array}$ & $\begin{array}{c}\text { Antecedent dry } \\
\text { weather period } \\
(\mathrm{d})\end{array}$ \\
\hline 18 & 4.4 & 2 & 2.2 & 3.8 & 7.5 \\
\hline 21 & 6.6 & 6 & 1.1 & 2.4 & 2.8 \\
\hline 25 & 2.6 & 4 & 0.65 & 1.6 & 4.3 \\
\hline 26 & 24.4 & 16 & 1.5 & 3.6 & 0.8 \\
\hline 28 & 1.8 & 1 & 1.8 & 1.8 & 2.1 \\
\hline
\end{tabular}


Data monitoring performed each five minutes allows a good understanding of the sewer system. It shows that during dry weather period, flow, turbidity and conductivity evolved in the same time. This is due to human and industrial activities. For these parameters, a minimum is observed during the night between 3 and 6 a.m. Then a maximum is observed around 11 a.m. The rain event of the $18^{\text {th }}$ November leads an important increase of flow and turbidity. This one represents one and a half time the flow during dry weather. This increase induces discharged in the receiving environment by the main CSO of the study site. On the other side, conductivity decreases by 2 times compared to the one usually measured during dry weather. A similar evolution is observed for the rain event of the 21st. Then major rain event of $26^{\text {th }}$ induces a flow increase by a factor of 4.4 compared to the flow during dry weather. Conductivity decreases a lot during this event but turbidity is approximately the same as the one during dry weather period. At the end of the month, turbidity, conductivity and flow haven't reached yet dry weather values.

Using correlation functions, this data can be converted in TSS, COD and total nitrogen concentrations and will be used to establish mass/volume curves and to calculate pollutant fluxes.

\subsection{Mass/volume curves}

In the literature, the dimensionless mass/volume curves are often use to characterize first flush effect and network behavior during rain events (Barco et al. [12]; Li Li-qing et al. [13]; Bertrand-Krajewski et al. [14]). Measurements every 5 minutes allow carrying out precise mass/volume curves. Figure 4 shows mass/volume curves for the three major rain events that have occurred in November $\left(18^{\text {th }}, 21^{\text {st }}\right.$ and $\left.26^{\text {th }}\right)$.

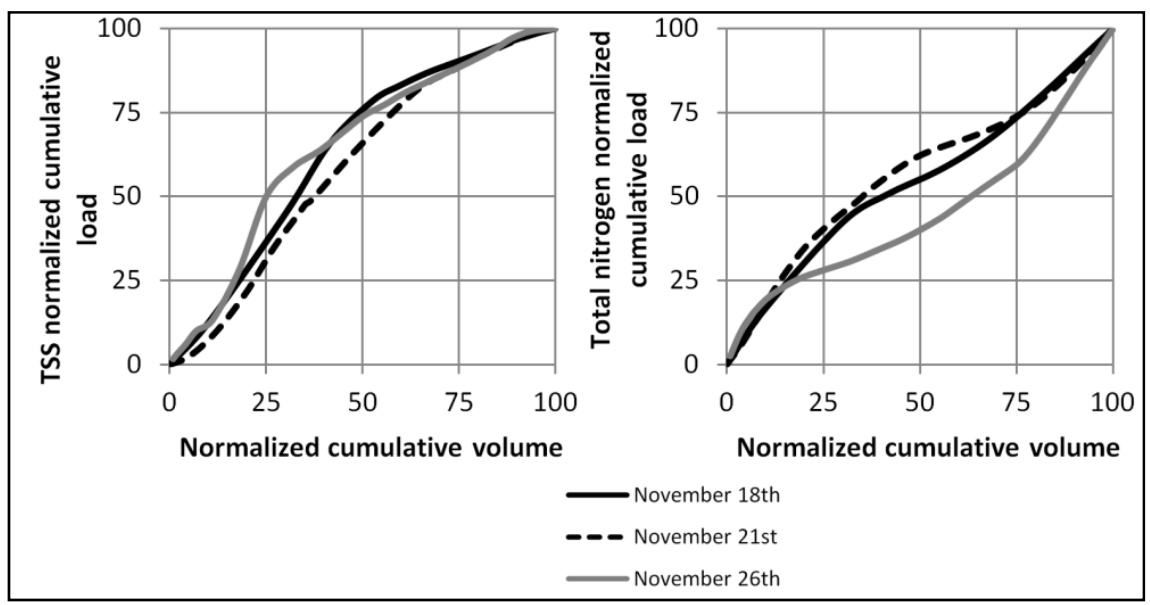

Figure 4: TSS and total nitrogen normalized cumulative load versus normalized cumulative volume. 
This figure shows that for TSS the three mass/volume curves are globally similar (as COD follows the same trend as TSS, it is not presented here). As define by Bertrand-Krajewski et al. [14], a first flush phenomenon occurs if at least $80 \%$ of the total pollutant mass is transported in the $30 \%$ of volume during a rainfall event. In this study, according to this definition, there is no first flush during these rain events for TSS. Nevertheless, the repartition of mass pollutant versus volume is not linear. For $50 \%$ of volume, the mass of TSS ranges between 60 and $80 \%$. This is important information for wastewater management in the case of possible wastewater storage. Continuous monitoring of turbidity allows analyzing an important number of rain events and leads to a better understanding of sewer network.

For total nitrogen, these curves are different from TSS ones because for $50 \%$ of volume, the mass of total nitrogen is between 60 and $40 \%$. So there is no first flush effect for total nitrogen. This difference can be due to the dissolved form of nitrogen (Kafi et al. [15]) that is not subjected to sedimentation, accumulation and erosion in case of rain events. The rain event of November $26^{\text {th }}$ is different than the others as $50 \%$ of the total volume corresponds to $40 \%$ of the total mass of nitrogen. This can be due to the large quantity of water during this event which dilutes wastewater.

\subsection{Daily fluxes of pollutants}

The amount of data gathered the Figure 3 makes the interpretation difficult. To enable processing of this information over a long time period (a month or more), another method is proposed. A summary of these data as fluxes of pollutants has been performed. Figure 5 shows the results obtained for TSS fluxes, flow and TSS concentrations values.

It is interesting to compare the three parameters studied: fluxes, flow and TSS concentration. A low rain event induces an increase in TSS fluxes during the day as shown on the $18^{\text {th }}$ and the $21^{\text {st }}$ of November. The total volume does not change significantly but the concentration is higher than during dry weather period. This is due to the erosion of stocks in the network and to the "washing" of impervious surfaces. Nevertheless, TSS concentration during the second rain event is slightly lower (20\%) than for the first one. That mean that there are still stocks in the network but they are decreasing.

Then, rain event of November $26^{\text {th }}$ induces a considerable increase of TSS fluxes (factor of 4 compared to the dry period) this is due to an important rain event so a large increase of volume (4.5 times the flow of dry weather period). That means that this rain event brings TSS load again even after previous rain events. Two hypotheses can be made. The first one is that in-sewer stocks were reconstituted in five dry weather days. The second one is that bigger increase of flow leads to a stronger erosion of in-sewer stocks. Probably both options have some truth. 


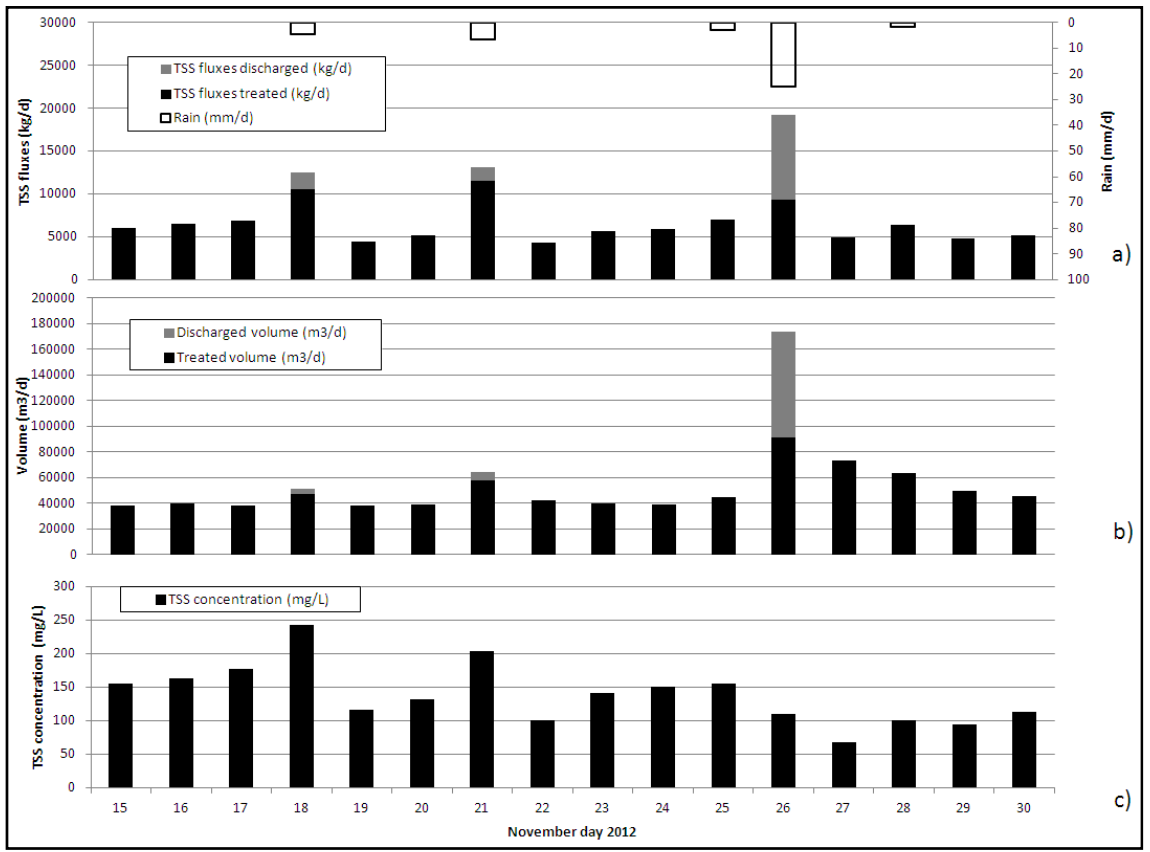

Figure 5: $\quad$ TSS fluxes $(\mathrm{kg} / \mathrm{d})$ and rain $(\mathrm{mm} / \mathrm{d})$ (a) volume $\left(\mathrm{m}^{3} / \mathrm{d}\right)$ (b) and TSS concentration (mg/L) (c).

After these rain events, at the end of the month, total flow decreases step by step and reaches the dry weather level after 4 days. In the same time, TSS concentration is always lower than the one of dry weather period. This can be probably explained by an amount of SS which are settling at the bottom of the sewer. This continuous monitoring and presentation allows the direct determination of discharged TSS fluxes that is a very important data for the impact assessment on receiving waters. This discharged load is not really significant for the two first events (about $1700 \mathrm{~kg} /$ day) but it is really considerable for the major rain event as about $10000 \mathrm{~kg}$ of SS are discharged into the receiving stream. Knowing the flow and the pollutant concentration in the receiving stream the sanitation manager can evaluate the contribution of this discharge into the receiving water.

Figure 6 shows the total nitrogen fluxes, the rain, the total volume and the concentration of total nitrogen for the study period. Total nitrogen fluxes level off during all the study period even in the case of important rain event. Slight increase is observed the $26^{\text {th }}$ during the major rain event. That means that rain does not provide nitrogen in large amount. Total fluxes stay steady; nitrogen is essentially diluted by rain water. This is because nitrogen is mainly present under dissolved form: from 95 to $70 \%$ (Kafi et al. [15]). So it is not subjected to deposition and erosion phenomenon. Like for TSS, this continuous monitoring allows to know the total nitrogen discharge fluxes. For rain events of $18^{\text {th }}$ and 
$21^{\text {st }}$ the discharged fluxes are low (about $10 \%$ of the total fluxes) but for the rain event of $26^{\text {th }}, 30 \%$ (500 kg), of the total nitrogen is discharged. In the same time $50 \%$ of the volume is discharged.

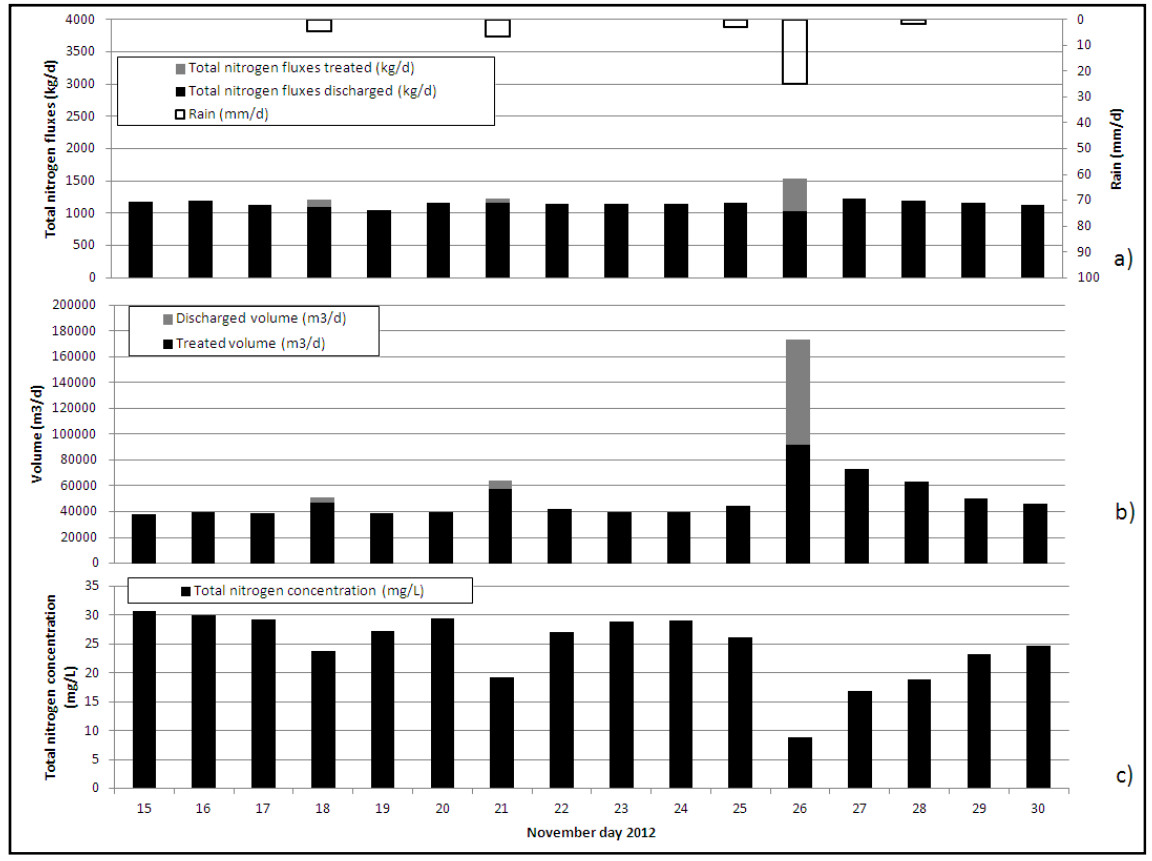

Figure 6: Total nitrogen fluxes $(\mathrm{kg} / \mathrm{d})$ and rain $(\mathrm{mm} / \mathrm{d})(\mathrm{a})$ volume $(\mathrm{m} 3 / \mathrm{d})(\mathrm{b})$ and total nitrogen concentration $(\mathrm{mg} / \mathrm{L})(\mathrm{c})$.

\section{Conclusion}

Using turbidity and conductivity measurements to estimate continuous concentrations of pollutants in the sewage system of the CDAPP has been validated and is working for several months. This tool allowed making easier the monitoring of wastewater. It is possible to obtain an instantaneous and continuous estimation of the pollutant concentration which is very interesting for the sanitation manager. Then, this study examined different ways to process the data. The study of raw data allows a general monitoring and behaviour of sewerage. However, from this information, other uses are possible as the construction of curves mass/volume. Thus, it is possible to compare the behaviour of the sewage system during different rainfall events. Finally, pollutant fluxes can be calculated daily. This allows summarizing the information and to process large data sets (month, year) leading to a global monitoring that can take into account all situations (weather, activities, seasons) encountered in the study area. Subsequently, the use of this system is possible in all applications relating to wastewater. 


\section{References}

[1] Water Framework Directive (2000) 2000/60/EC Directive of the European Parliament and the Council of October 2000 establishing a framework for Community action in the field of water policy. Official Journal of the European Communities from 22.12.2000, 327/1, 327/72.

[2] Gromaire M.C., Garnaud S., Saad M., Chebbo G., Contribution of different sources to the pollution of wet weather flows in combined sewers, Water research 352 521-5332001.

[3] Chebbo G., Gromaire M.C., The experimental urban catchment "le Marais" in Paris: what lessons can be learned from it? Journal of Hydrology 299 312-323 2004.

[4] Gasperi J., Garnaud S., Rocher V., Moilleron R., Priority pollutants in wastewater and combined sewer overflow, Science of the total environment 407 263-272 2008.

[5] Lacour C., Joannis C., Chebbo G., Assessment of annual pollutant loads in combined sewers from continuous turbidity measurements: Sensivity to calibration data, Water research 43 2179-2190 2009.

[6] Joannis C., Ruban G., Aumond M. et al. Implementation of turbidity sensors in sanitation network, Techniques Sciences Méthodes, $n^{\circ} 1 / 2$, pp 21312010 (in French).

[7] Métadier M., Bertrand-Krajewski J.-L., The use of long-term on-line turbidity measurements for the calculation of urban stormwater pollutant concentrations, loads, pollutographs and intra-event fluxes, Water Research, 46 6836-6856 2012.

[8] Lawler D.M., Petts G.E., Foster I.D.L, Harper S., Turbidity dynamics during spring storm events in an urban headwater river system: The Upper Tame, West Midlands, UK Science of the total environment 360 109-126 2006.

[9] Aumond M., Joannis C., Continuous measurement of turbidity in a separate sewer system: implementation and first results, La houille blanche $n^{\circ} 4$, pp 121-128 2006 (in French).

[10] Boutayacht M., Del Grand D., Galliot B., Turbidity applied to the management of a wastewater storage basin in Nancy, Techniques Sciences et Méthodes, n¹/2 pp 69-71 2010 (in French).

[11] Rosier F., Dupont H., Roux C., Guillon A., Using turbidity to manage dry weather wastewater. Techniques Sciences et Méthodes, n¹/2 pp 81-83 20102010 (in French).

[12] Barco J., Papiri S., Stenstrom M.K., First flush in a combined sewer system, Chemosphere 71 827-833 2008.

[13] Li L., Yin C., He Q., Kong L., First flush of storm runoff pollution from an urban catchment in China, Journal of Environmental Sciences 19 295-299 2007.

[14] Bertrand-Krajewski J.L., Chebbo G., Saget A., Distribution of pollutant mass vs volume in stormwater discharges and the first flush phenomenon, Water Research 328 2341-2356 1998. 
162 Water Resources Management VII

[15] Kafi M., Gasperi J., Moilleron R., Gromaire M.C., Chebbo G., Spacial variability of the characteristics of combined wet weather pollutant loads in Paris Water Research 42 539-549 2008. 